Polymer Journal, Vol. 38, No. 8, pp. 743-756 (2006)

(C) 2006 The Society of Polymer Science, Japan

[AWARD ACCOUNT: SPSJ WILEY AWARD (2005)]

\title{
$\pi$-Electronic Soft Materials Based on Graphitic Nanostructures
}

\author{
Takanori FUKUSHIMA $^{\dagger}$ \\ ERATO-SORST Aida Nanospace Project, Japan Science and Technology Agency, \\ National Museum of Emerging Science and Innovation, 2-41 Aomi, Koto-ku, Tokyo 135-0064, Japan
}

(Received May 24, 2006; Accepted June 19, 2006; Published July 24, 2006)

\begin{abstract}
This review focuses on our recent studies on the development of soft materials consisting of graphitic nanostructures. We found that single-walled carbon nanotubes, when suspended in imidazolium ion-based ionic liquids and ground in an agate mortar, form physical gels (bucky gels), where entangled nanotube bundles are exfoliated to give highly dispersed, much finer bundles. The use of polymerizable ionic liquids as the gelling media leads to the formation of highly electroconductive polymer/nanotube composites, which show a dramatic enhancement in mechanical properties. Bucky gels allow the fabrication of the first printable actuator that operates for a long time in air at low applied voltages. We also succeeded in the development of a new family of nanotubular graphite through self-assembly of amphiphilic hexabenzocoronene derivatives. The nanotube consists of a graphitic wall formed from a great number of $\pi$-stacked hexabenzocoronene units, which provide a charge carrier transport pathway. Suitable chemical modifications of the amphiphile resulted in the formation of nanotubes with various interesting properties. Details of the design, properties, and scope of such $\pi$-electronic soft nanomaterials are described herein. [doi:10.1295/polymj.PJ2006042]

KEY WORDS Nanotube / Nanomaterial / Soft Material / Graphene / Self-Assembly / $\pi$-Electronic System / Ionic Liquid /
\end{abstract}

A two-dimensional (2D) honeycomb network of $s p^{2}$-hybridized carbon is known as graphene, which stacks in a three-dimensional regular order to form graphite, a traditional carbon material. While the isolation and electronic properties of a single-layered graphene was reported quite recently, ${ }^{1-3}$ the $2 \mathrm{D}$ carbon layer has drawn considerable attention in relation to carbon nanotubes. Carbon nanotubes are cylindrical carbon nanoclusters with an extremely high aspect ratio, which are formed by rolling-up of a graphene sheet (Figure 1). ${ }^{4}$ Since their discovery, ${ }^{5,6}$ not only such an interesting structural aspect but also the extraordinary electronic and mechanical properties of carbon nanotubes have fascinated researchers in many fields, thereby leading to remarkable advances in nanoscience and nanotechnology over the last decade.
On the other hand, graphene can be regarded as one of the ultimate structural aspects of $\pi$-conjugated system. Although any methodologies in organic synthesis are currently inaccessible to the infinite 2D carbon layer, organic chemists can design its molecular fragments, i.e., polycyclic aromatic hydrocarbon (PAHs), bearing desired functions. As graphene stacks to form graphite, PAHs possess strong tendency to form one-dimensional columnar structures via $\pi$-stacking interactions. Since such unidirectionally aligned assemblies of PAHs can provide anisotropic charge carrier and energy transport pathways, PAHs have been considered as promising components for molecular electronic and optoelectronic devices. $^{7-10} \mathrm{We}$ were motivated to explore novel materials based on graphitic nanostructures, in particular, focusing on one-dimensional (a)

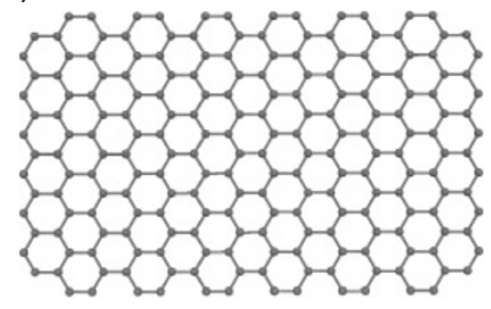

(b)

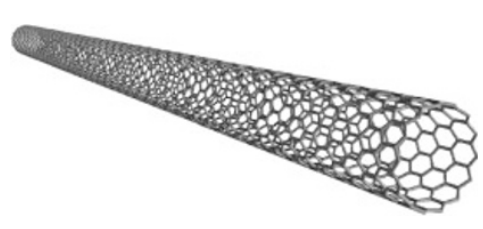

(c)

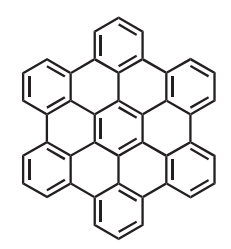

Figure 1. Schematic structures of (a) graphene, (b) carbon nanotube, and (c) hexa-peri-hexabenzocoronene (a molecular graphene).

${ }^{\dagger}$ To whom correspondence should be addressed (Tel: +81-3-3570-9182, Fax: +81-3-3570-9183, E-mail: fukushima@nanospace.miraikan.jst. go.jp). 
objects including carbon nanotubes and columnar assemblies derived from graphene-like molecules (Figure 1). This Account will give an overview of our recent works on the development of soft $\pi$-electronic materials in view of the fabrication, properties, and scope of the applications.

\section{SOFT MATERIALS COMPOSED OF CARBON NANOTUBES AND IONIC LIQUIDS}

\section{Carbon Nanotube Gel of Ionic Liquids (Bucky Gels)}

Due to their extraordinary electronic and mechanical properties as well as the unique structural aspect, ${ }^{4}$ numerous potential applications of carbon nanotubes have been proposed. ${ }^{11}$ However, for practical applications, one of the essential problems arises from their extremely poor processability. Carbon nanotubes usually exist as bundles, which are heavily entangled with one another to form agglomerates. For a better ability of processing as well as chemical and physical modifications of nanotubes, adsorption of organic molecules onto the surface via van der Waals and $\pi$-stacking interactions has been investigated, ${ }^{12-15}$ yet the development of facile and practical processing methods still remains as a challenging issue. In this regard, we were interested in the use of ionic liquids for the processing of the nanotubes, with an expectation that cationic species potentially interact with the $\pi$-electronic surface through so-called cation- $\pi$ interaction. ${ }^{16}$ In the course of this study, we serendipitously found an unexpected phenomenon that imidazolium ionsbased ionic liquids ${ }^{17-19}$ (Figure 2) form physical gels, upon grinding with single-walled carbon nanotubes (SWNTs). ${ }^{20}$ SWNT gels of ionic liquids, which we call 'bucky gels,' can readily be prepared by grinding suspensions of SWNTs (HiPco SWNT) in ionic liquids, followed by the removal of excess liquid components. The gelation takes place with $0.5-1 \mathrm{wt} \%$ of SWNTs. Bucky gels thus obtained, can readily be

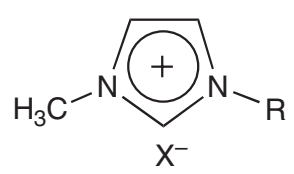

$$
\begin{aligned}
& \mathrm{EMIBF}_{4}: \mathrm{R}=\mathrm{C}_{2} \mathrm{H}_{5}, \mathrm{X}=\mathrm{BF}_{4} \\
& \mathrm{BMIBF}_{4}: \mathrm{R}=n-\mathrm{C}_{4} \mathrm{H}_{9}, \mathrm{X}=\mathrm{BF}_{4} \\
& \mathrm{HMIBF}_{4}: \mathrm{R}=n-\mathrm{C}_{6} \mathrm{H}_{13}, \mathrm{X}=\mathrm{BF}_{4} \\
& \mathrm{BMIPF}_{6}: \mathrm{R}=n-\mathrm{C}_{4} \mathrm{H}_{9}, \mathrm{X}=\mathrm{PF}_{6} \\
& \text { BMITf }_{2} \mathrm{~N}: \mathrm{R}=n-\mathrm{C}_{4} \mathrm{H}_{9}, \mathrm{X}=\left(\mathrm{CF}_{3} \mathrm{SO}_{2}\right)_{2} \mathrm{~N}
\end{aligned}
$$

Figure 2. Molecular structures of imidazolium ion-based ionic liquids.

processed. For example, via extrusion from a syringe, one can fabricate a bucky gel string, which is not easily broken even when suspended (Figure 3a). Due to the non-volatility of ionic liquids, bucky gels, in sharp contrast with ordinary organo- and hydrogels, are highly stable and can retain their physical properties even under a reduced pressure.

Interestingly, upon gelation, the heavily entangled SWNT bundles exfoliate to give highly dispersed, much finer bundles, as observed by TEM microscopy (Figures $3 b$ and $3 c$ ). On the other hand, electronic absorption and Raman spectral profiles SWNTs did not show any disruption of SWNTs, indicating that the gelation is triggered only physically. Based on the results of DSC and X-ray diffraction analyses in conjunction with the rheological properties of the bucky gels, we presume that the system is more likely ruled by a great number of weak physical crosslinks among the SWNT bundles, for which molecular ordering of ionic liquids is considered responsible. SWNTs may orient imidazolium ions on their $\pi$-electronic surfaces via a possible cation- $\pi$ interaction. Such a molecular ordering may trigger clustering of the surrounding imidazolium ions in the bulk solvent phase and interconnect neighboring SWNT bundles to form a physical (a)

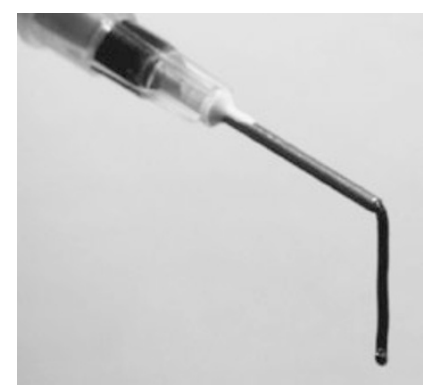

(b)

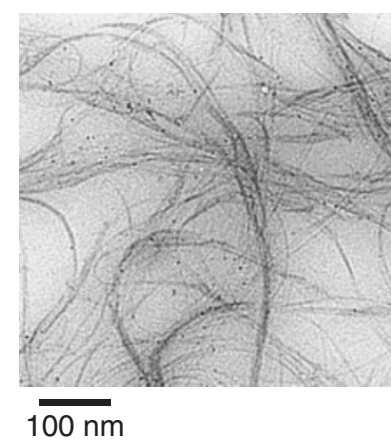

(c)

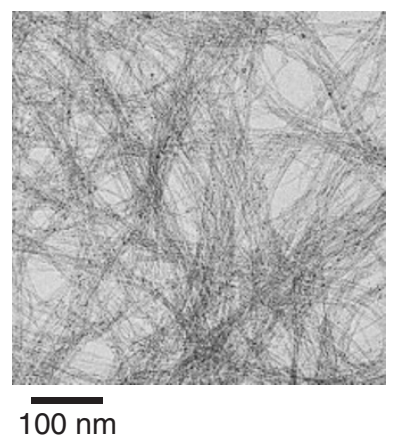

Figure 3. (a) Photograph of a bucky gel. (b) TEM micrograph of SWNTs obtained by dispersion of a bucky gel of BMIBF 4 in deionized water. (c) TEM micrograph of as-received SWNTs as reference, after sonication in ethanol. 
crosslink. Namely, the bundles are weakly interlocked with one another, and the system therefore behaves as a gel. Upon grinding, the large bundles of SWNT are disentangled into many finer bundles, which efficiently promote the ordering of ionic liquids. This phenomenon is reminiscent of biological mineralization, where local clustering of inorganic salts on the surface of an organic scaffold triggers controlled nucleation and growth of inorganic crystals.

\section{Carbon Nanotube-Reinforced Polymeric Materials Derived from Ionic Liquids}

SWNTs have been expected to behave as excellent dopants for the fabrication of electroconductive polymer materials with enhanced mechanical properties. ${ }^{21}$ Young's modulus of individual SWNTs was reported to be as large as $\sim 1 \mathrm{TPa},{ }^{22-24}$ which is even comparable to that of graphite in-plane, and the electrical conductivities of bulk SWNTs are very high in an order of $10^{2}-10^{3} \mathrm{~S} \mathrm{~cm}^{-1} \cdot{ }^{25}$ However, a strong tendency of SWNTs to form agglomerate hampers homogeneous doping in polymers, giving rise to rather poor enhancement of mechanical and conductive properties. Hence, it is important to seek materials that allow efficient dispersion of SWNTs into polymer. Moreover, if polymers themselves can disperse SWNTs by their strong interfacial interactions, one can expect much greater effects of doped SWNTs on the resulting polymer materials.

We anticipated that the use of polymerizable imidazolium ion-based ionic liquids as gelling media allows fabrication of a mechanically reinforced, electroconductive soft material. In fact, when the bucky gels prepared from acrylate- or methacrylate-appended ionic liquid (Figure 4) were subjected to in-situ free-radical polymerization, the resulting polymeric materials (bucky plastic) exhibited dramatically enhanced mechanical and conductive properties. ${ }^{26}$ For example, a film sample (Figure 5a) of a bucky plastic prepared from the methacrylate monomer, displayed an excellent conductivity of $1 \mathrm{~S} \mathrm{~cm}^{-1}$ and a 120 -fold enhancement of Young's modulus at a $7 \mathrm{wt} \%$ content of
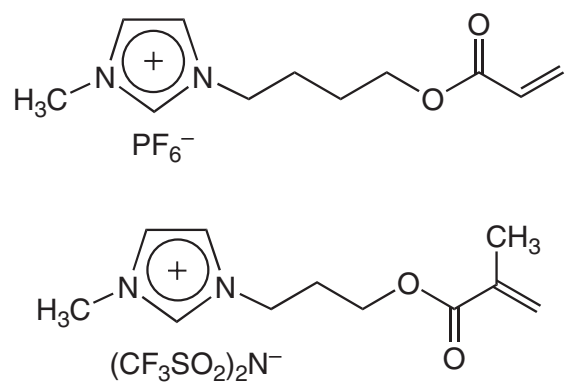

Figure 4. Molecular structures of imidazolium ion-based polymerizable ionic liquids. (a)

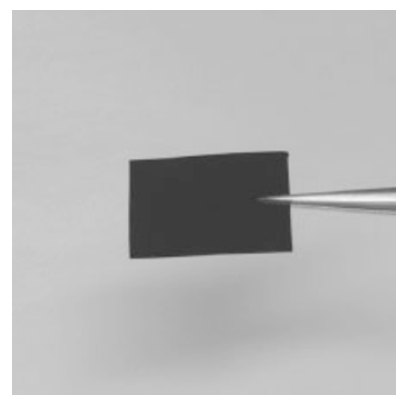

(b)

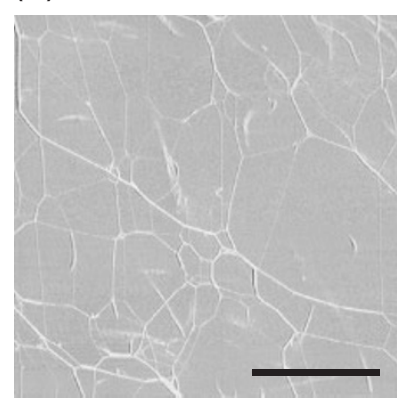

Figure 5. (a) Photograph of a bucky plastic film. (b) AFM phase image of the film surface. Scale bar, $1 \mu \mathrm{m}$.

SWNTs. Such a large enhancement of tensile modulus by SWNTs has not been reported for SWNT-doped polymeric materials. Furthermore, the observed conductivity is one of the highest values so far reported for SWNT-doped polymers $\left(s<10^{-2} \mathrm{~S} \mathrm{~cm}^{-1}\right)$ at comparable loading levels of SWNTs. SEM and AFM micrographs of the bucky plastic film displayed the presence of crosslinked networks consisting of finely dispersed SWNTs (Figure 5b). Such nanotube networks that develop in the polymer matrix may not only suppress slipping of entrapped polymer molecules via a strong interfacial interaction, but also facilitate an intertubular charge carrier transport.

\section{Bucky Gel Actuators}

Since bucky gels are a soft composite consisting of a nano-electrode (SWNT) and a non-volatile electrolyte (ionic liquid), they are promising material for the component of electrochemical devices. ${ }^{27-29} \mathrm{We}$ indeed succeeded in the development of the first dry actuator, which can be simply fabricated by casting. ${ }^{30}$ Our bucky gel actuator adopts a bimorph configuration (Figure 6) with a polymer-supported internal ionic liquid electrolyte layer, sandwiched by bucky gel electrode layers, which allows quick and long-lived operation in air at low applied voltages.

The actuator film can be readily fabricated by layerby-layer casting of the electrode and electrolyte components in gelatinous $\mathrm{PVdF}(\mathrm{HFP})$-containing 4-methyl-2-pentanone. In sharp contrast with precedent conjugated polymer actuators, the fabrication process includes neither deposition of metallic layers nor electrochemical polymerization. In a typical example, the bucky gel electrode layers include $13 \mathrm{wt} \%$ of SWNTs, $54 \mathrm{wt} \%$ of $\mathrm{BMIBF}_{4}, 33 \mathrm{wt} \%$ of $\mathrm{PVdF}(\mathrm{HFP})$, and the electrolyte layer contains $67 \mathrm{wt} \%$ of $\mathrm{BMIBF}_{4}$ and $33 \mathrm{wt} \%$ of PVdF(HFP). When an electric potential of $\pm 3.5 \mathrm{~V}$ was applied with a frequency of $0.01 \mathrm{~Hz}$, an actuator strip underwent bending motion toward the anode side (Figure 7) with the maximum displacement of $5 \mathrm{~mm}$. The strain and stress generated in the 


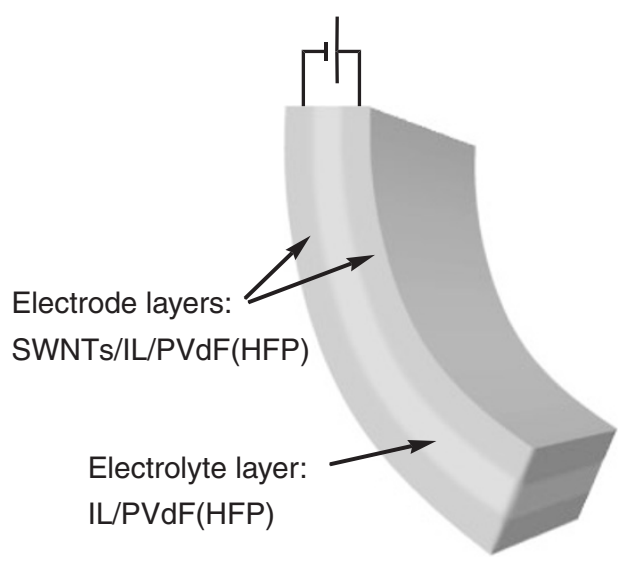

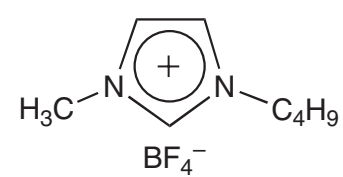

$\mathrm{IL}=\mathrm{BMIBF}_{4}$

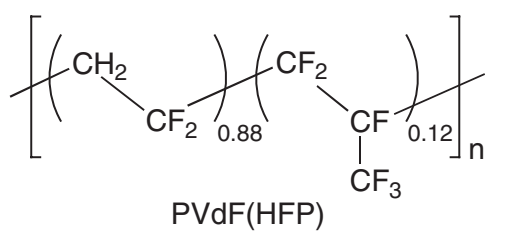

Figure 6. Schematic representation of an actuator strip consisting of a polymer-supported ionic liquid electrolyte layer sandwiched by bucky gel electrode layers.
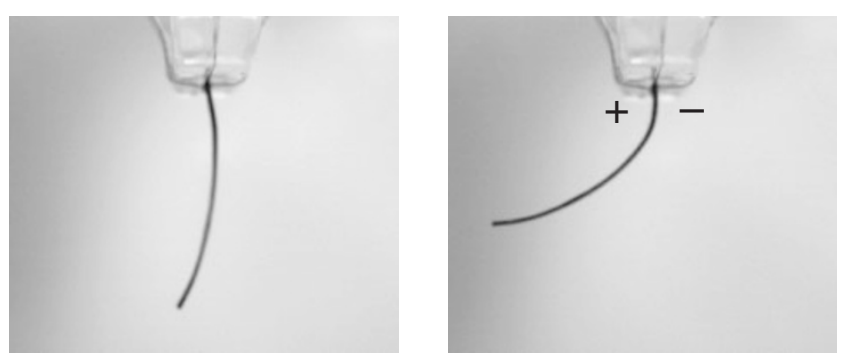

Figure 7. Bending motion of an actuator strip $(15 \mathrm{~mm}$ in length, $1 \mathrm{~mm}$ in width, $0.28 \mathrm{~mm}$ in thickness) at an applied voltage of $\pm 3.5 \mathrm{~V}$ with a frequency of $0.01 \mathrm{~Hz}$.

bucky gel electrode layer were determined as $0.9 \%$ and $0.1 \mathrm{MPa}$, respectively. Baughman and co-workers reported that SWNT sheets, laminated together with a double-sided Scotch tape, show an electrochemical actuation in aqueous electrolyte solutions, where the SWNT sheets not only serve as electrodes but also undergo elongation/contraction upon charge injection into the nanotubes. ${ }^{31}$ However, taking the low loading level of SWNTs (13 wt \%) into account, such a large strain $(0.9 \%)$ cannot be explained only by the elongation/contraction of SWNTs. We rather consider that volume changes of the electrode layers, caused by an interlayer ion transport, possibly contribute to the actuation.

The actuation took place quickly and perfectly responded to an alternating voltage $( \pm 3.0 \mathrm{~V})$ even at $30 \mathrm{~Hz}$. In the actuator, the electrode and electrolyte layers are seamlessly connected with one another, thereby facilitating intra- and interlayer ion transports, essential for the quick response. We also confirmed that the actuation $( \pm 2.0 \mathrm{~V}, 0.1 \mathrm{~Hz})$ could be repeated at least 8,000 cycles in air without notable decay (20\%). The above observations are outstanding, because no polymer actuator that demonstrates such a prominent overall performance in air has yet been developed. Furthermore, soft matter-based, easy proc- essing of bucky gel actuator allows for the fabrication of actuators with desired shapes, which could be combined with printing technologies for patterning.

\section{SELF-ASSEMBLED GRAPHITIC NANOTUBES FROM AMPHIPHILIC MOLECULAR GRAPHENES}

\section{Design of Self-Assembled Nanotubes with Electronic Functions}

Carbon nanotubes are certainly superb nanomaterials in view of physical properties, whereas they have a drawback arising from difficulty of chemical functionalization. In the course of the studies on bucky gel, we were motivated to elaborate new $\pi$-electronic soft nanotubes with chemically accessible surfaces using self-assembly of chemically programmed molecular building blocks. Although such bottom up, supramolecular approaches have shown potentials for the controlled synthesis of nanotubular objects, ${ }^{32-34}$ those possessing tailored electronic functions had not yet been developed. To this end, we chose hexa-perihexabenzocoronene (HBC) (Figure 1) as a building block. HBC is a graphene fragment and known to have a strong tendency to stack together via $\pi$-stacking interactions. The first synthesis and characterization of HBC was reported by Clar and coworkers. ${ }^{35}$ Müllen and coworkers have discovered that chemical modification of its periphery with long alkyl chains leads to the formation of discotic liquid-crystalline materials, which exhibit high charge-carrier mobilities. ${ }^{7-10}$ On the other hand, we introduced an amphiphilicity into $\mathrm{HBC}$ skeleton as a programming for controlled self-assembly. We expected that amphiphilic HBC could self-assemble in polar solvents to form a bilayer tape consisting of $\pi$-stacked HBC units, a potential precursor for tubular structure. ${ }^{36}$ After many attempts along this concept, we eventually succeeded in the fabrication of well-defined, non-cova- 


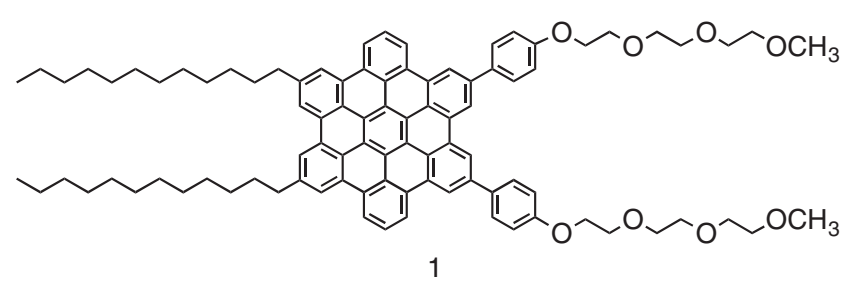

Figure 8. Molecular structure of Gemini-shaped hexa-perihexabenzocoronene (HBC) amphiphile $\mathbf{1}$.

lent graphitic nanotubes using Gemini-shaped amphiphilic HBC 1 (Figure 8). ${ }^{37}$ The wall of the nanotube consists of a great number of the molecular graphene stacked parallel to the longer axis of the tube.

\section{Synthesis and Characterization of Self-Assembled Graphitic Nanotubes}

The controlled self-assembly of HBC amphiphile 1 into the graphitic nanotubes can be triggered when a THF solution of $1(1 \mathrm{mg} / \mathrm{mL})$ is heated at $50^{\circ} \mathrm{C}$ and allowed to cool to room temperature. Filtration of the resulting suspension allows the isolation of the nanotube as a yellow-colored solid substance (Figure 9a), which shows characteristic red-shifted absorption bands at 426 and $459 \mathrm{~nm}$. As displayed by TEM mi-

(a)

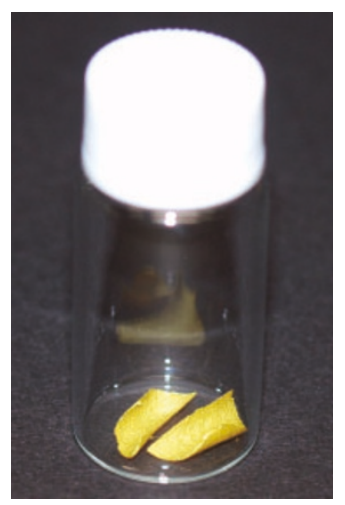

(c)

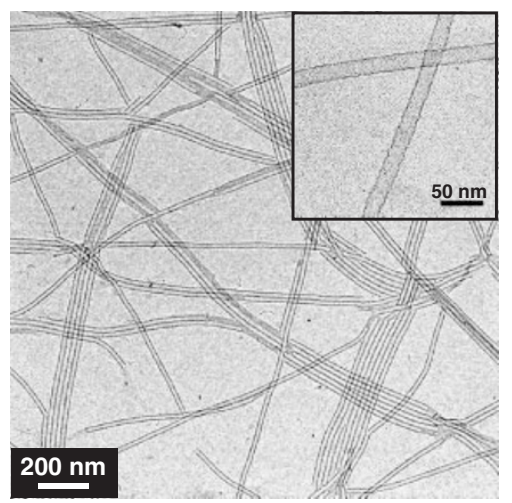

crograph (Figure 9c), the nanotubes have a uniform diameter $(20 \mathrm{~nm})$ and wall thickness $(3 \mathrm{~nm})$. Hence, the diameter of graphitic nanotube is one order of magnitude larger than single-walled carbon nanotubes. It is also worth noting that only a few tubular assemblies of small organic molecules have been obtained in this size regime. Electron diffraction analysis indicated the presence of $\pi$-stacked HBC units in the nanotube with a plane-to-plane separation of $3.6 \AA$. This value is comparable with that of the (002) diffraction of graphite $(3.35 \AA)$. A SEM micrograph allows the visualization of the hollow morphology (Figure 9b). We assumed that the graphitic nanotubes are formed by rolling-up of a two-dimensional pseudo-graphite tape composed of $\pi$-stacked 1 (Figure 10). Fortunately, this was confirmed by the presence of both coiled and tubular objects in the TEM micrographs (Figures 9d) observed when 1 was self-assembled in a mixture of THF/water $(80 / 20 \mathrm{v} / \mathrm{v})$. Considering the molecular structure and dimension of $\mathbf{1}$, the wall thickness of the nanotube $(3 \mathrm{~nm})$ suggests a bilayer structure of the precursor tape (Figure 10b). This bilayer tape most likely consists of two single-layered graphitic tapes, each composed of bilaterally coupled one-dimensional HBC columns. Here, the long alkyl

(b)

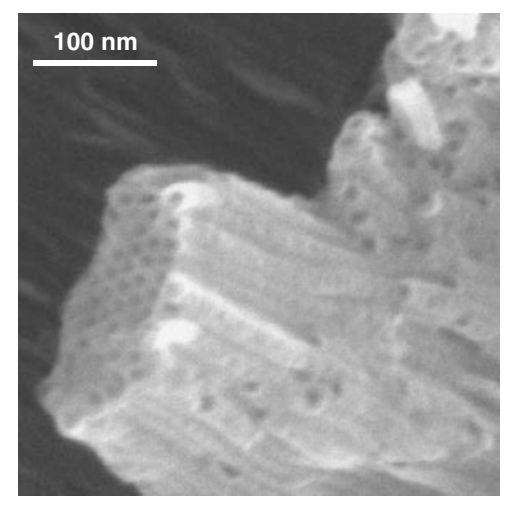

(d)

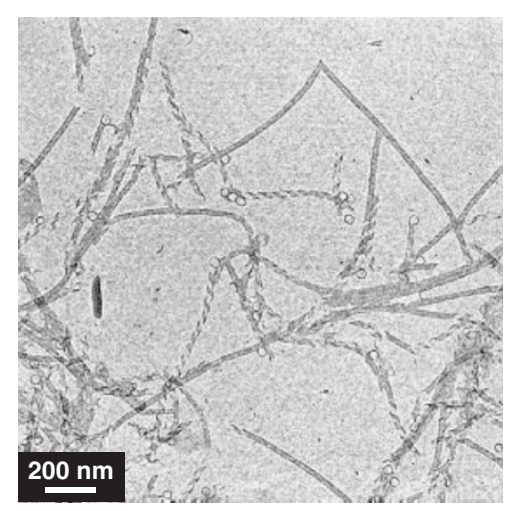

Figure 9. (a) Photograph of a filtered sample of graphitic nanotubes formed from 1. (b) SEM and (c) TEM micrographs of graphitic nanotubes formed by self-assembly of $\mathbf{1}$ in THF. (d) TEM micrograph of self-assembled $\mathbf{1}$, obtained as a suspension in water-containing $\mathrm{THF} /$ water $(80 / 20 \mathrm{v} / \mathrm{v})$. 
(a)

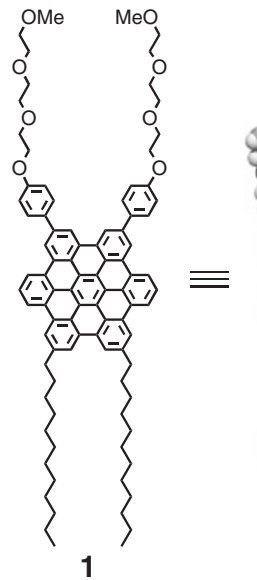

(b)

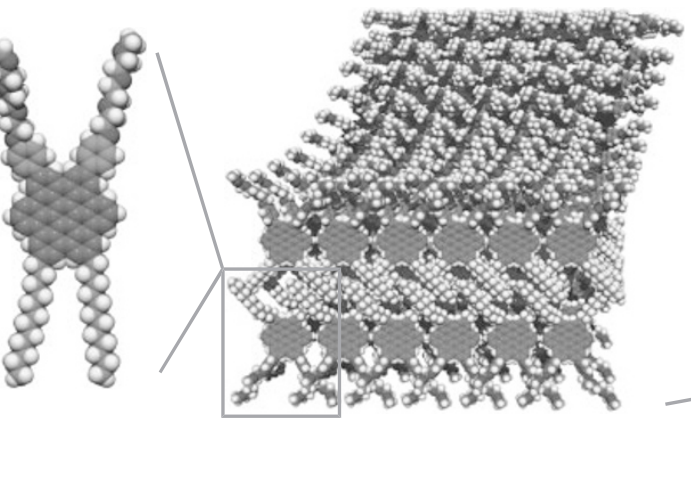

(c)

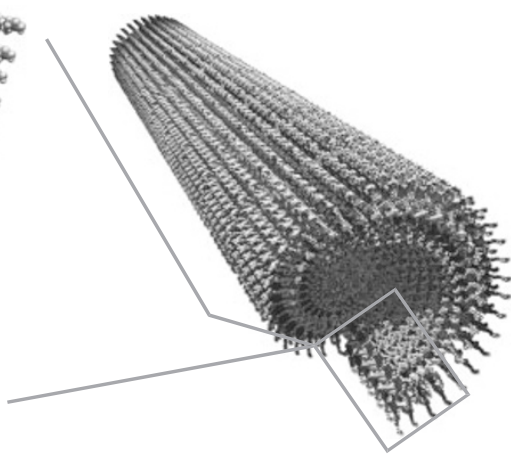

Figure 10. Schematic structures of (a) HBC amphiphile 1, (b) self-assembled bilayer tape, and (c) graphitic nanotube.

chains are interdigitated to hold the bilayer structure, while the hydrophilic TEG chains, located on the surface of the tape, should suppress the formation of multilayer structures in a polar solvent such as THF.

\section{Structural Aspects of Self-Assembled Graphitic Nano- tubes}

From a topological point of view, multi-walled carbon nanotubes can be thought of a family of graphite, ${ }^{5}$ because they possess structural characteristics of graphite in their tubular architectures, where curved graphene sheets stacked perpendicularly to the longer axis of the tubes. In this sense, our nanotube is a new family of molecularly-engineered, one-dimensional graphite. Our molecular design strategy takes full advantage of the amphiphilic HBCs, which prohibits the three-dimensional growth of a self-assembled structure, which is commonly observed for non-amphiphilic HBC molecules. Given that the precursor bilayer tape is $22 \mathrm{~nm}$ wide, a $10 \mu \mathrm{m}$-long nanotube roughly consists of $2 \times 16$ unidirectionally aligned $\pi$-stacked columns, each composed of $5 \times 10^{4}$ molecules of HBC. Such a discrete, defect-free, long-range molecular ordering is outstanding.

\section{Electrical Properties of Self-Assembled Graphitic Nanotubes}

Since HBC derivatives are redox active, ${ }^{38}$ charge carriers should be generated in the graphitic nanotube upon oxidation. Thus, we investigated if a single piece of our graphitic nanotube is electroconductive. For this conductivity measurement, a single piece of the nanotube was positioned by chance across Pt nanogap $(180 \mathrm{~nm})$ electrodes on a $\mathrm{SiO}_{2}$ substrate. While the intact nanotube was essentially insulating, the nanotube after oxidation with $\mathrm{NOBF}_{4}$ clearly showed a conducting $I-V$ profile with an ohmic behavior. The conductivity decreased as the temperature was lowered, indicating that the oxidized nanotube is a semi- conductor. From the $I-V$ profile, the resistivity at $285 \mathrm{~K}$ was determined to be $2.5 \mathrm{M} \Omega$. The electrical conduction observed for our nanotube is rather interesting because it is realized by a long-range intermolecular electronic communication through the graphitic molecular arrays. ${ }^{39}$

\section{Graphitic Nanotubes with One-Handed Helical Array of $H B C$}

Hexa-peri-hexabenzocoronene graphitic nanotubes consist of helically rolled-up bilayer tapes formed from bilaterally coupled columns of $\pi$-stacked HBC units. Hence, they have chirality as a structural element. While self-assembly of an achiral component should give a racemic mixture of right- and left-handed helical nanotubes, incorporation of a stereogenic center into the hydrophobic or hydrophilic side chains of HBC 1 is expected to cause a stereochemical bias to either the right- or left-handed helical HBC array in the resulting nanotubular assembly (Figure 11). To examine this idea, we designed chiral HBC amphiphiles $\mathbf{2}$ and $\mathbf{3}$ (Figure 12) that bear a point chirality in the hydrophilic and hydrophobic side chains, respectively.

Controlled assembly of $\mathbf{2}$ takes place in 2-methyltetrahydrofuran (MeTHF) to form a nanotubular object whose size regime is identical to that of graphitic nanotube derived from $\mathbf{1}$. We found that translation of the point chirality of $\mathbf{2}$ into supramolecular helical chirality occurs to form the nanotubes with either right- or left-handed helical senses ${ }^{40}$ For example, a hot MeTHF solution of $\mathbf{2 S}(3 \mathrm{mg} / \mathrm{mL})$, when rapidly cooled to $20^{\circ} \mathrm{C}$, showed a time-dependent spectral change, where red-shifted absorption bands at 398 and $421 \mathrm{~nm}$, characteristic of graphitic nanotubes, appeared with an isosbestic point at $382 \mathrm{~nm}$ (Figure 13a). While the solution of $2 \mathrm{~S}$ at $50^{\circ} \mathrm{C}$ was silent in circular dichroism (CD) spectroscopy, cooling of the solution resulted in the appearance of positive CD 
bands at 389, 400, and $423 \mathrm{~nm}$ (Figure 13b). Since the red-shifted absorption bands are CD-active, the optical activity of the system is originated from the $\pi$-stacked HBC units in the nanotubular assembly. We also confirmed that the $\mathrm{CD}$ spectral profiles of the enantiomer $\mathbf{2 R}$ (Figures $13 \mathrm{c}$ and 13d) are perfect mirror images of those observed for $\mathbf{2 S}$. On the other hand, chiral HBC amphiphile $\mathbf{3}$ bearing branched asymmetric centers in the paraffinic side chains hardly gave nanotubular assemblies. It is plausible that the branched side chains of $\mathbf{3}$ prevent the formation of a bilayer tape, essential for nanotube formation.

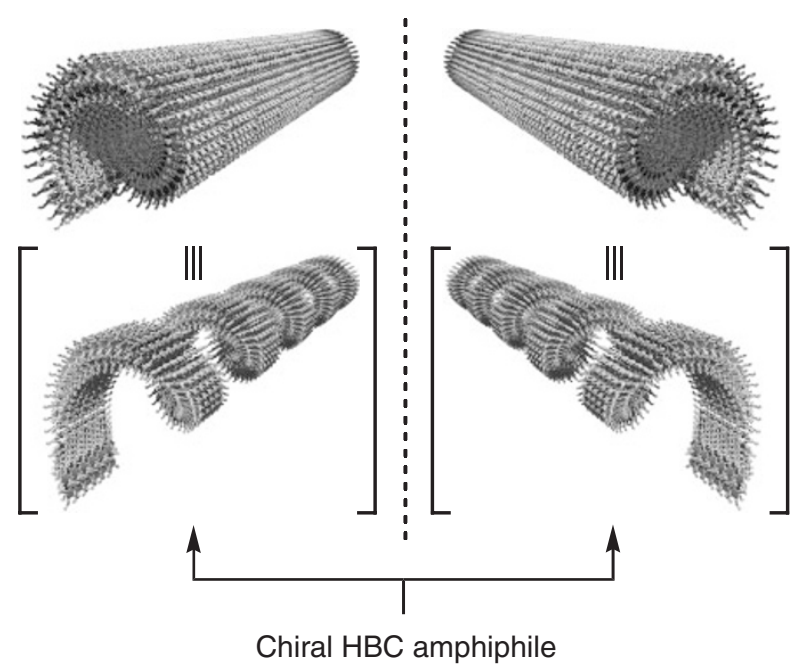

Figure 11. Formation of chiral graphitic nanotubes via translation of point chirality of HBC amphiphile into supramolecular helical chirality of the nanotube.

(a)

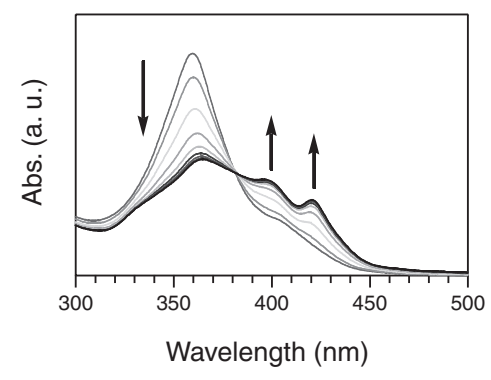

(c)

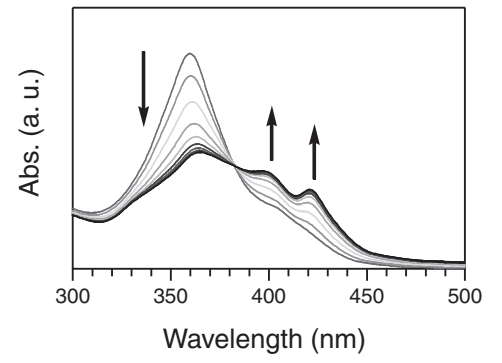

Conductive polymers with helical architectures have attracted attention in view of the concept of molecular solenoids..$^{41,42}$ However, this concept has not yet been realized because there are no molecular objects that fulfill certain requisites for conductivity and helicity. This work demonstrated the first example
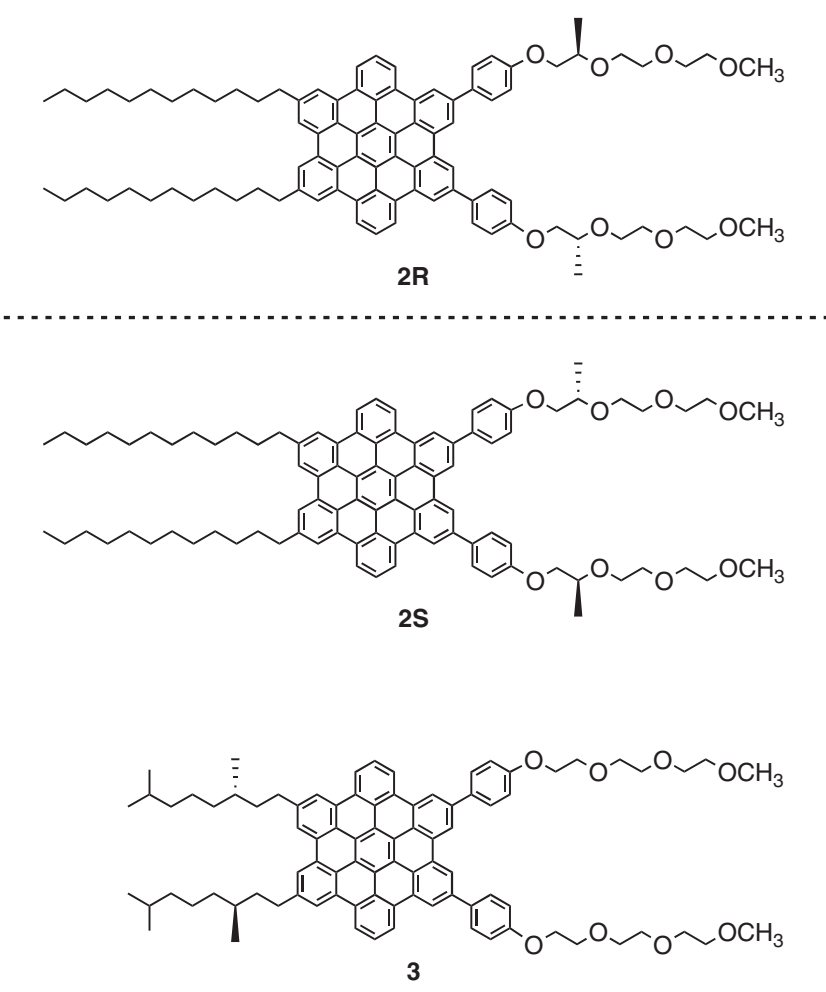

Figure 12. Molecular structures of chiral HBC amphiphiles 2 and $\mathbf{3}$.

(b)

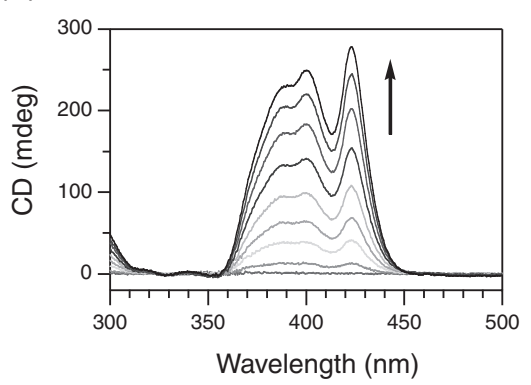

(d)

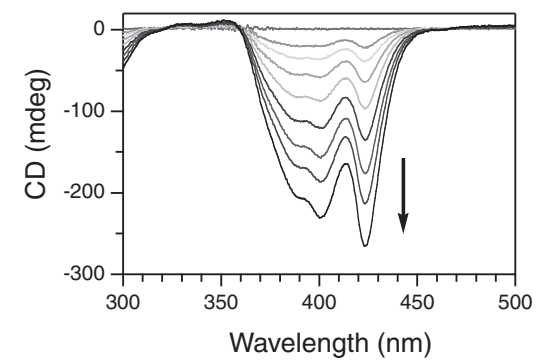

Figure 13. Time-dependent changes in electronic absorption and CD spectra of $\mathbf{2 S}(\mathrm{a}, \mathrm{b})$ and $\mathbf{2} \mathbf{R}(\mathrm{c}, \mathrm{d})$ in $\mathrm{MeTHF}(3 \mathrm{mg} / \mathrm{mL})$ at $20{ }^{\circ} \mathrm{C}$ on rapid cooling from $50^{\circ} \mathrm{C}$. 


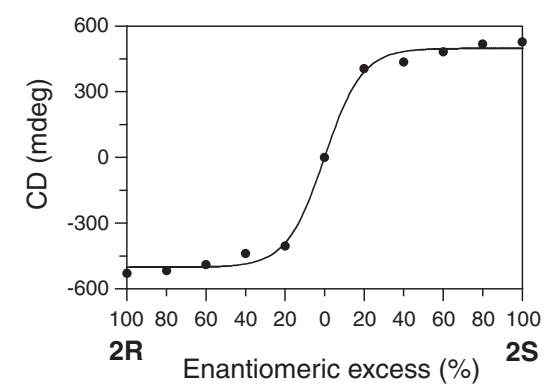

Figure 14. Change in CD intensity at $423 \mathrm{~nm}\left(20^{\circ} \mathrm{C}\right)$ by varying mole ratios of the enantiomers of $\mathbf{2}$. For the self-assembly, the mixtures of the enantiomers were heated in MeTHF $(3 \mathrm{mg} / \mathrm{mL})$ at $50^{\circ} \mathrm{C}$ and allowed to cool to $20^{\circ} \mathrm{C}$. The $\mathrm{CD}$ spectra were measured after $12 \mathrm{~h}$.

of conductive tubular objects possessing a helical chirality, and therefore may also provide a synthetic strategy toward realization of molecular solenoids. In this system, we also found an interesting phenomenon that the $(S)$ - and $(R)$-enantiomers co-assemble at varying mole ratios to give nanotubes. Even though the enantiomeric excess of the chiral amphiphile was changed over a wide range from 20 to $100 \%$, the CD spectrum of the suspension remained almost unchanged, resulting in a sigmoidal response of the CD intensity $(423 \mathrm{~nm})$ against the optical purity of $\mathbf{2}$ (Figure 14). The chiroptical profiles also suggest the absence of enantiomerically enriched domains in the helical nanotubes. Such a non-linear phenomenon is referred to as majority rule-type chirality amplification, ${ }^{43-46}$ where the major enantiomer incorporated into each nanotube determines the helical sense. Although chirality amplification under the operation of the majority rule is well known for covalent helical polymers, this had been unprecedented in supramolecular systems. ${ }^{47,48}$

\section{Covalent Stabilization of Graphitic Nanotubes}

Self-assembly of preprogrammed molecular building blocks has been recognized as a useful method for the synthesis of soft materials with a nanometric precision. ${ }^{49,50}$ However, a lack of structural robustness inherent to non-covalent architecture could be one of the drawbacks of such supramolecular materials. Thus, physical stabilization of self-assembled nanoobjects through covalent bonds is an important subject for practical applications of supramolecular chemistry. ${ }^{51-53}$ Along this line, we designed HBC amphiphile 4 bearing allylic functionalities at the termini of the oxyalkylene chains. ${ }^{54}$ Since the hydrophilic chains cover both inner and outer surfaces of graphitic nanotubes (Figure 10), we initially expected that acyclic diene metathesis (ADMET) ${ }^{55}$ of preformed nanotubes of 4 (Figure 15) can lead to the formation of surfacepolymerized nanotubes (Figure 16). Although com- (a)

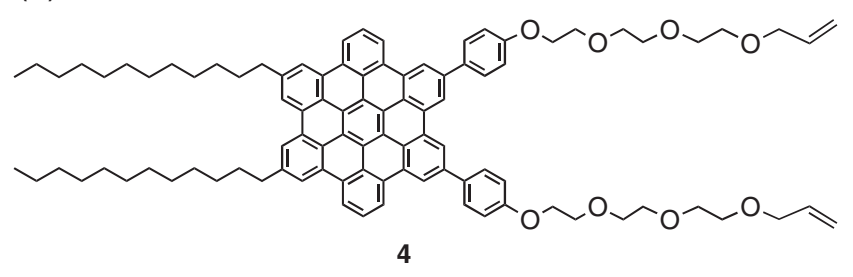

(b)

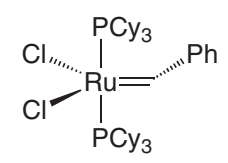

Figure 15. Molecular structures of (a) HBC amphiphile $\mathbf{4}$ and (b) Grubbs catalyst employed.
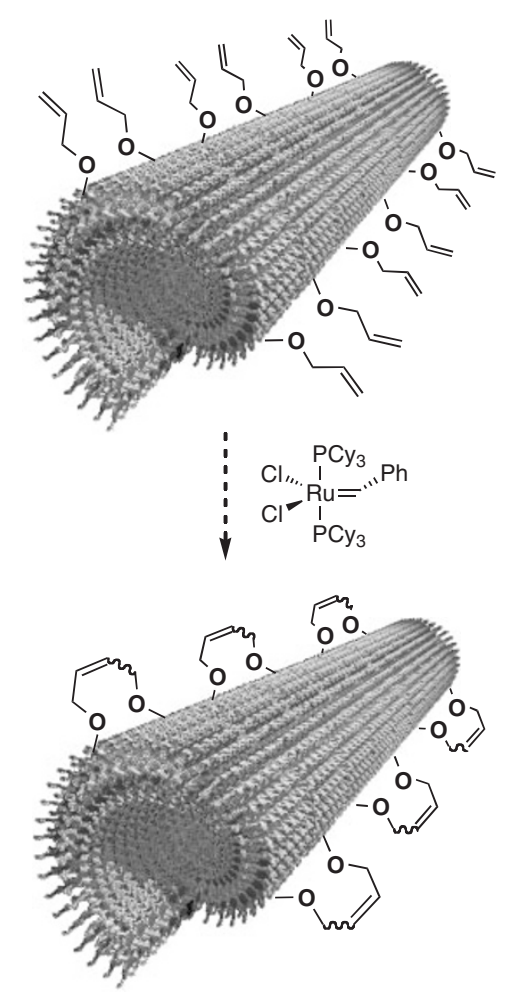

Figure 16. Schematic representation for the formation of polymerized graphitic nanotube through ADMET of 4 .

pound 4 self-assembled in THF to yield a nanotubular object, ADMET of the resulting nanotubes using a Grubbs catalyst ${ }^{55}$ was sluggish. As a result, the reaction mixture showed, even after 4 days, a major MALDI-TOF MS peak due to the monomer along with small peaks corresponding to short-chain oligomers. On the other hand, we noticed with a big surprise that ADMET of $\mathbf{4}$ in $\mathrm{CH}_{2} \mathrm{Cl}_{2}$ resulted in the formation of graphitic nanotubes with a polymerized surface with a nearly quantitative conversion of the allylic functionalities into internal olefins. The TEM and SEM micrographs of surface-polymerized nanotubes are depicted in Figure 17. It should be noted that 
(a)

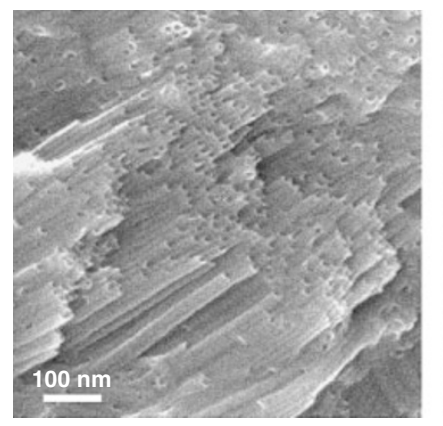

(b)

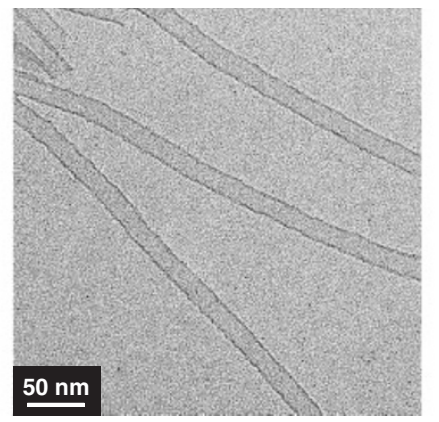

(c)

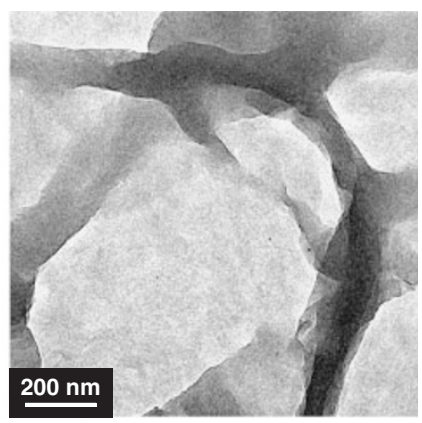

Figure 17. (a) SEM micrograph of a solid product isolated from the ADMET mixture of 4 in $\mathrm{CH}_{2} \mathrm{Cl}_{2}$ at $25^{\circ} \mathrm{C}$ for $3 \mathrm{~d}$. (b) TEM micrograph of an air-dried ADMET mixture of 4 in $\mathrm{CH}_{2} \mathrm{Cl}_{2}$ at $25^{\circ} \mathrm{C}$ for $3 \mathrm{~d}$. (c) TEM micrograph of an air-dried $\mathrm{CH}_{2} \mathrm{Cl}_{2}$ solution of 4 .

compound 4 is highly soluble in $\mathrm{CH}_{2} \mathrm{Cl}_{2}$, where no tubular assemblies forms even by slow evaporation (Figure 17c). These facts indicate that the ADMET triggers spontaneous formation of the polymerized nanotubes from 4, assembled only dynamically in solution, if any. The surface polymerization significantly enhances the thermal stability of the graphitic nanotube. DSC analyses showed that the polymerized nanotubes possess a higher softening temperature $\left(244^{\circ} \mathrm{C}\right)$ than that of the non-polymerized version $\left(195^{\circ} \mathrm{C}\right)$. Furthermore, polymerized nanotubes preserved their hollow structure much longer upon heating. For example, most of the polymerized nanotubes survived though heating at $175^{\circ} \mathrm{C}$ for $24 \mathrm{~h}$, whereas the morphology of the non-polymerized nanotubes was completely disrupted within $2 \mathrm{~h}$.

Our finding of ADMET-triggered formation of polymerized nanotubes is remarkable, considering a general understanding that polymerization of dynamic assemblies usually gives rise to irregular aggregates. Although a large number of examples are known for the covalent stabilization of self-assembled molecular objects by post polymerization or crosslinking, ${ }^{56-60}$ controlled self-assembly triggered by bond-forming chemical reactions is unprecedented. The polymerized graphitic nanotubes possess chemically accessible olefinic functionalities on the surface, which may allow the fabrication of composites with a variety of substances with different functions.

\section{NEW APPLOARCHES TOWARD ONE- DIMENSIONAL COLUMNAR ASSEMBLIES FORMED FROM MOLECULAR GRAPHENES}

Stabilization of One-Dimensional Columnar Assembly by Interionic Interactions

Due to their one-dimensional charge or energy transport capabilities, ${ }^{61,62}$ discotic liquid crystals $^{63}$ consisting of polycyclic aromatic hydrocarbons (PAHs) are promising materials for the application of molecular electronic and optoelectronic devices. ${ }^{9,10}$ From this point of view, development of discotic liquid crystals having a broad mesophase range as low as room temperature is an important subject. ${ }^{64,65}$ However, such liquid crystals generally possess high crystal-to-mesophase transition temperatures. In addition, attempts to lower the crystallization temperature usually result in lowering the clearing temperature. We envisioned that incorporation of imidazolium ions to the alkyl side chains of PAH-based liquid crystals allows the stabilization of the mesophases. Since ionic liquids are liquid over a wide temperature range, even at cryogenic temperatures, such functionalities could prevent crystallization of the side chains. Furthermore, interionic interactions among them may stabilize the columnar assembly of a PAH moiety.

A new class of triphenylene (TP) 5 thus designed (Figure 18), whose termini are covalently attached to 1-methylimidazolium tetrafluoroborate $\left(\mathrm{BF}_{4}\right)$, indeed forms a columnar LC mesophase over a wide temperature range $\left(47-111^{\circ} \mathrm{C}\right.$ ) (Figures 19a and 20a). ${ }^{66}$ This

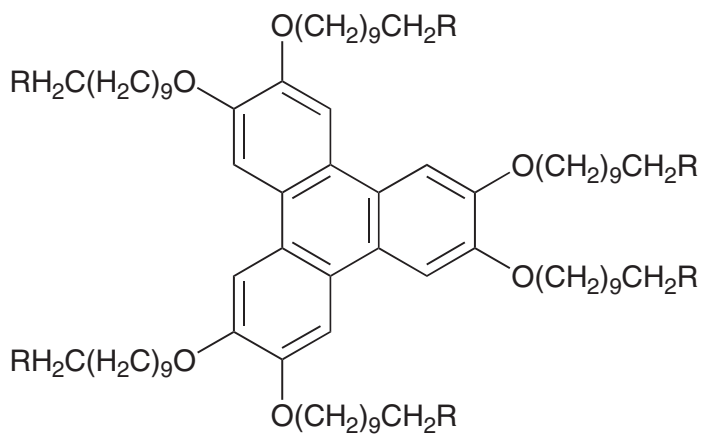<smiles></smiles>

Figure 18. Molecular structures of triphenylene derivatives 5 and 6. 
(a)

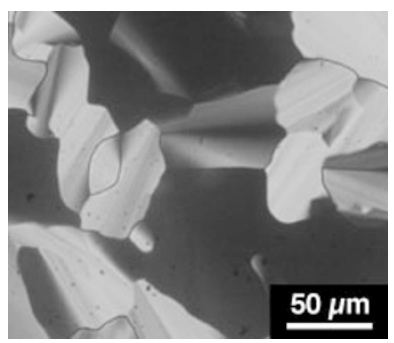

(b)

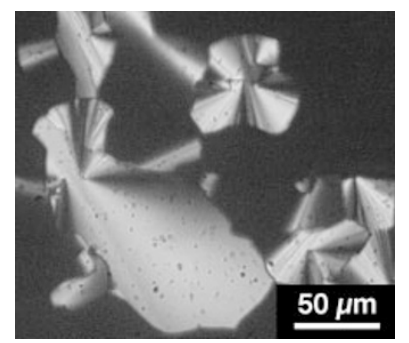

Figure 19. Optical textures of (a) 5 at $103^{\circ} \mathrm{C}$ and (b) an equimolar mixture of $\mathbf{5}$ and $\mathrm{HMIBF}_{4}$ at $25^{\circ} \mathrm{C}$, observed under crossed polarizing conditions of a microscope on cooling from the isotropic liquids at a rate of $1^{\circ} \mathrm{C} \mathrm{min}^{-1}$.

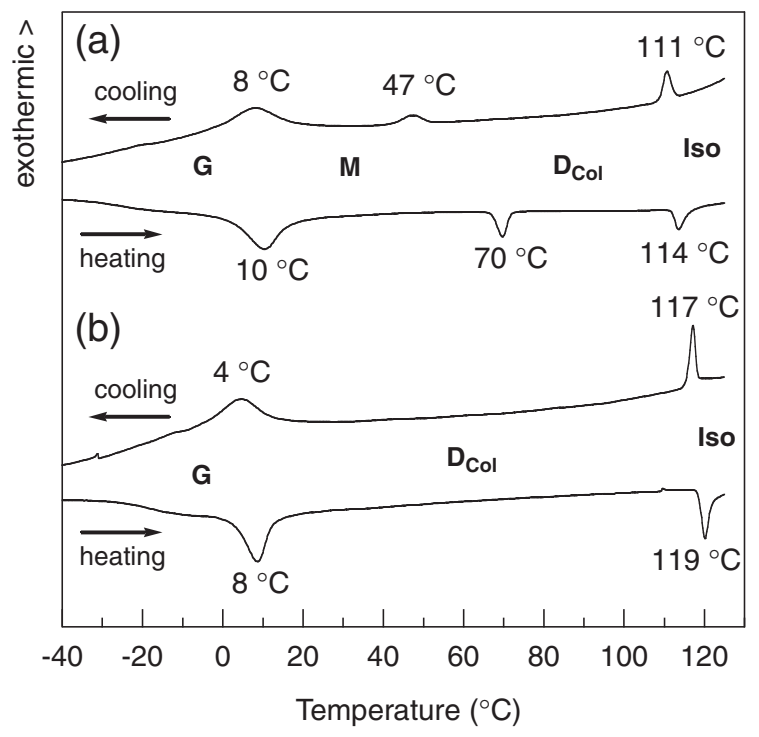

Figure 20. DSC profiles (second heating/cooling cycle, scan rate; $10{ }^{\circ} \mathrm{C} \mathrm{min}^{-1}$ ) of (a) $\mathbf{5}$ and (b) an equimolar mixture of $\mathbf{5}$ and $\mathrm{HMIBF}_{4} . \mathrm{G}$, glassy state; $\mathrm{M}$, mesophase; $\mathrm{D}_{\mathrm{Col}}$, discotic columnar mesophase; Iso, isotropic liquid.

observation is outstanding because paraffinic TP 6 (Figure 18) without imidazolium ion functionalities has been reported to form a columnar mesophase only in a much narrower temperature range $\left(58-69^{\circ} \mathrm{C}\right) .{ }^{67}$ Interestingly, upon mixing with an equimolar amount of 1-hexyl-3-methylimidazolium tetrafluoroborate $\left(\mathrm{HMIBF}_{4}\right.$, Figure 2), the temperature range of the columnar LC phase is significantly expanded from $47-111$ to $4-117^{\circ} \mathrm{C}$ (Figures $19 \mathrm{~b}$ and $20 \mathrm{~b}$ ). We presume that the imidazolium salt functionalities of $\mathbf{5}$ in the LC mesophase form a pseudo network by their interionic interaction, which stabilizes the columnar assembly to a certain extent. When an appropriate amount of $\mathrm{HMIBF}_{4}$ is added to the system, it presumably participates into and reinforces the interionic network, so that the columnar mesophase is retained even at $4{ }^{\circ} \mathrm{C}$. Although the mesophase of $\mathbf{5}$, in the absence of $\mathrm{HMIBF}_{4}$, displayed only weak XRD peaks,<smiles>Oc1cc2c3cc(O)c(O)cc3c3cc(O)c(O)cc3c2cc1O</smiles>

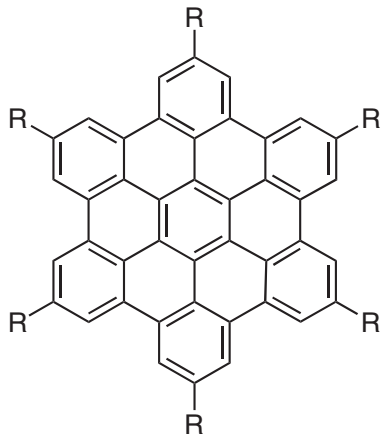

HBC 8

$\mathrm{R}=\left(\mathrm{CH}_{2}\right)_{8} \mathrm{CO}_{2}\left(\mathrm{OCH}_{2} \mathrm{CH}_{2}\right)_{3} \mathrm{OCH}_{3}$

Figure 21. Molecular structures of amphiphilic triphenylene (TP) 7 and hexa-peri-hexabenzocoronene (HBC) 8 .

the combination of $\mathrm{HMIBF}_{4}$ with $\mathbf{5}$ resulted in a notable enhancement of the diffraction intensity. The $\mathrm{XRD}$ pattern is assignable to a hexagonal columnar mesophase with a lateral core-to-core separation of $17.8 \AA$, which is in good agreement with the diameter of 5 with tightly folded side chains $(19 \AA)$. The above finding is not only important for a new possibility of ionic liquids in materials science, but may also contribute to the development of novel anisotropic soft materials for directional ion conductivity and charge transport. $^{68}$

Mesoporous Silica Composite Films with One-Dimensional Columnar Assemblies of Molecular Graphenes

Hexagonal mesoporous silica films have been expected as attractive materials for use in optical and optoelectronic applications because of their micrometer-scale thickness, high transparency, and capability of unidirectional alignment of guest substances in nanoscopic channels. ${ }^{69}$ By using $\pi$-conjugated amphiphilic molecules derived from TP $\mathbf{7}$ and HBC 8 as templates (Figure 21), we have succeeded in the development of novel mesoporous silica film whose channels are completely filled with one-dimensional columnar assemblies of disc-like molecules. ${ }^{70}$ For the fabrication of mesoporous silica film with a high structural regularity, we demonstrated a very simple and versatile method, which involves a maturing process by an EtOH vapor. Figure 22a shows a TEM micrograph of a mesoporous silica film containing selfassembled HBC 8, which clearly displays honeycomb architecture. The hexagonal regularity of the film was also confirmed by XRD analysis (Figure 22b). Since mesoporous silicates containing organic guests are interesting as they are potential precursors for low-dimensional carbon materials. For instance, pyrolysis of organic substances such as sucrose ${ }^{71}$ and acetylene ${ }^{72}$ in the mesoporous silicate channels has been reported 
(a)

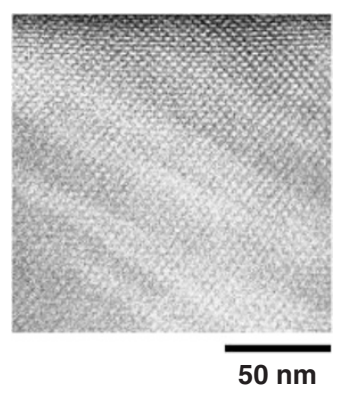

(b)

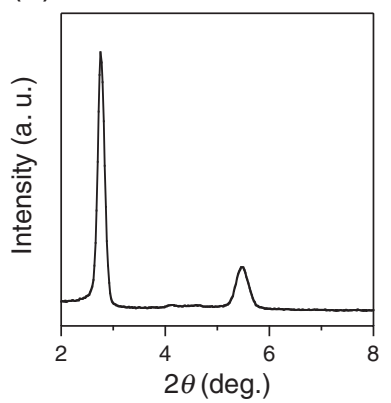

Figure 22. (a) TEM micrograph and (b) XRD pattern of a mesoporous silica film hybridized with $\mathbf{8}$.

to give mesoporous carbon and carbon nanotubes, respectively. Being motivated by these examples, we investigated pyrolysis of the $\pi$-stacked TP and HBC amphiphiles in the silicate channels. ${ }^{73}$ While no nanostructured carbon materials were obtained upon heating of these mesoporous silica composites, we noticed an unexpected phenomenon that the amorphous silicate framework was converted at $\geq 900{ }^{\circ} \mathrm{C}$ into cristobalite, a form of crystalline silica that appears at $1470-1713{ }^{\circ} \mathrm{C}$ in the phase diagram under an atmospheric pressure. Such a low-temperature formation of cristobalite promoted by amorphous carbon has never been reported. We consider that the radical character of the in situ generated amorphous carbon is likely responsible for this interesting phenomenon.

In fact, ESR spectroscopy indicated that the pyrolyzed silica contains carbon radical species with a spin concentration of $1.6 \times 10^{20}$ spins/g-carbon.

\section{Mesoporous Silica Composite Films with Charge- Transfer Assemblies}

Doping of suitable electron acceptors to paraffinic triphenylenes is known to result the formation columnar assemblies with an enhanced stability though charge-transfer (CT) interaction. ${ }^{74,75} \mathrm{We}$ reported the first example that mesoporous silica films can be fabricated using triphenylene-based CT complexes as templates for sol-gel synthesis, where amphiphilic triphenylene 7 (Figure 21) was used as an electron donor, while TNF, HAT, TCNQ, CA, and TCNB were employed as electron acceptors (Figure 23). ${ }^{76} \mathrm{By}$ virtue of the inorganic channels, we attained a longrange structural ordering of CT assemblies. The mesoporous silica films were highly transparent and colortunable from blue-to-red depending on the intercalating electron acceptor, and showed red-shifted CT absorption bands in the aligned silica nano channels. The hexagonal structure of the film was confirmed by TEM microscopy and XRD analysis. For example, a magnified TEM micrograph of the film (Figures 24), fabricated by 1:1 complex of $\mathbf{7}$ and TNF as a template, clearly displays hexagonally packed channels with a diameter of approximately $3 \mathrm{~nm}$. The honeycomb array is regularly aligned parallel to the substrate. The

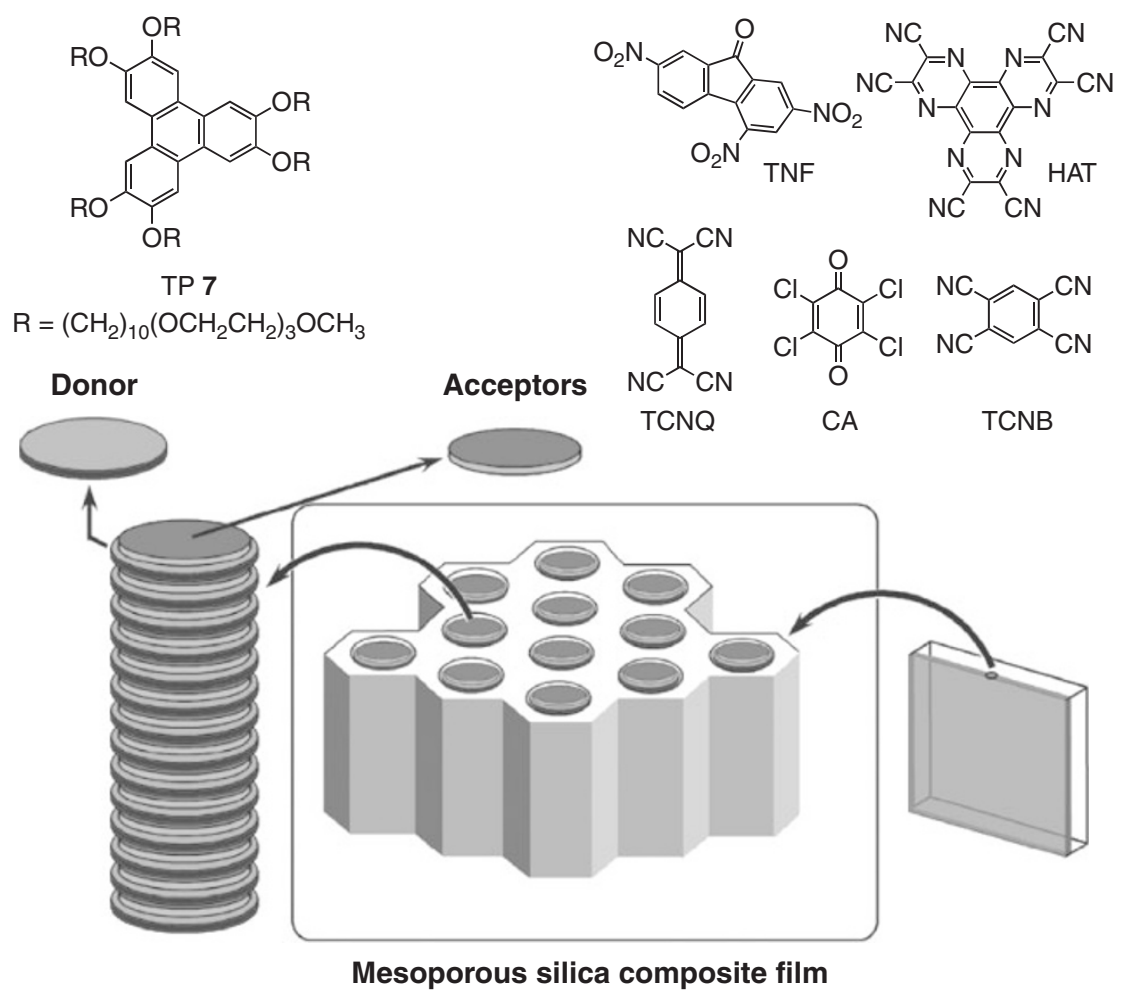

Figure 23. Molecular structures of electron donor and acceptors, and schematic representation of a mesoporous silica film containing one-dimensional columnar charge-transfer assemblies immobilized in a hexagonal array of nanoscopic channels. 


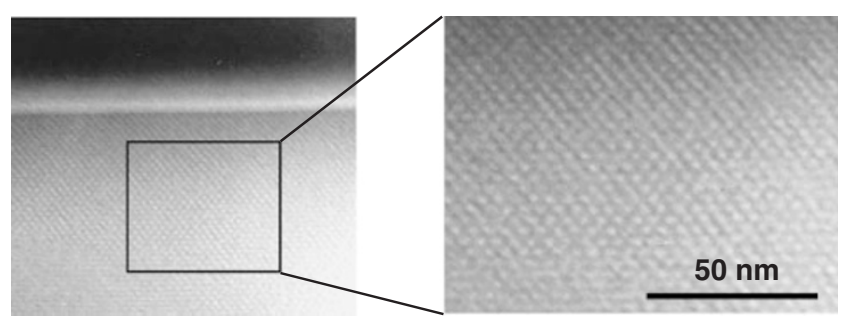

Figure 24. TEM micrographs of a cross-section of a mesoporous silica composite film prepared from an equimolar mixture of 7 and TNF.

(a)

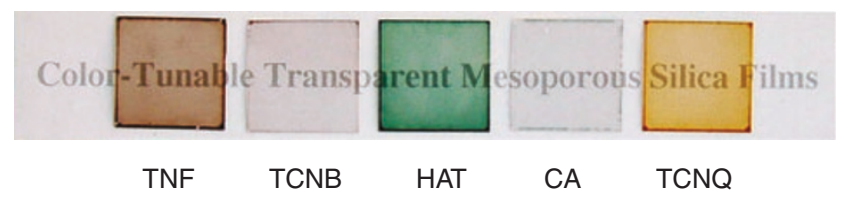

(b)

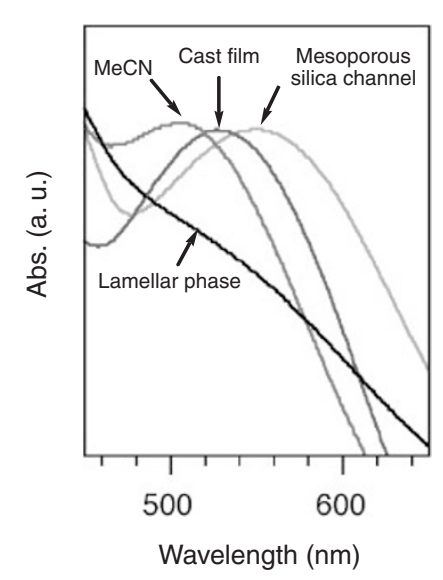

Figure 25. (a) Photograph of mesoporous silica films hybridized with CT assemblies composed of $\mathbf{7}$ and electron acceptors. (b) CT absorption bands of $7 / \mathrm{TCNB}$ complexes in a mesoporous silica film, a silica film with a lamellar structure, a cast film without silica, and an MeCN solution.

observed pore diameter is comparable to the molecular dimension of $\mathbf{7}$ with shrunk side chains, indicating that each silicate channel contains only one CT column. The donor/acceptor molar ratio can be varied over a wide range from 1:1 to 9:1.

CT absorption spectra of the silica films prepared with equimolar mixtures of $\mathbf{7}$ and TNF, TCNB, HAT, CA, and TCNQ showed absorption maxima at $490,548,615,700$, and $890 \mathrm{~nm}$, respectively. As exemplified by the case of silica film prepared with an equimolar mixture of $\mathbf{7}$ and TCNB, the CT absorption band $(548 \mathrm{~nm})$ were obviously red-shifted from those of the CT complexes in $\mathrm{MeCN}$ ( $2.0 \mathrm{mM}, 505$ $\mathrm{nm}$ ) and bulk phase (a cast film on a cover glass; $526 \mathrm{~nm}$ ) (Figure 25). Furthermore, the spectral profile of the composite silica film, prepared with $7 / \mathrm{TCNB}$ (1:1), remained unchanged when immersed for $12 \mathrm{~h}$ in $\mathrm{MeCN}$ and even in an MeCN solution of HAT, a stronger electron acceptor than TCNB. These observations indicate a defect-less structure of the composite silica film, where the included CT complex is highly stabilized within the nanoscopic channels and isolated from outer environments. The red shifts of the absorption maxima for the silica-immobilized CT may be due to an enhanced, long-range structural ordering of densely packed donor/acceptor assemblies within the nanoscopic silicate channels. CT complexes in solution and in the crystalline state have attracted much attention in the fields of organic chemistry, photochemistry, solid-state physics, and so forth. ${ }^{77}$ Therefore, immobilization of columnar CT assemblies in optically transparent solid supports may be one of the interesting subjects for materials sciences and device fabrications.

\section{CONCLUSIONS}

This review article describes our recent studies on novel soft materials consisting of graphitic nanostructures. Single-walled carbon nanotubes, when suspended in imidazolium ion-based ionic liquids and ground in an agate mortar, yield physical gels (bucky gels). In the gel, heavily entangled bundles of carbon nanotubes are exfoliated to give highly dispersed, much finer bundles. The use of polymerizable ionic liquids as the gelling media results in the formation of electroconductive polymer/nanotube composites with enhanced mechanical properties. Bucky gel is also an interesting material in view of the component of novel electrochemical devices. For example, bucky gels allow for the fabrication of a soft actuator, which operates in air for a long time without any external electrolytes. This article also highlights a new family of nanotubular graphite, which fabricated though self-assembly of amphiphilic hexabenzocoronene derivatives. The nanotubes consist of a graphitic wall composed of a great number of $\pi$-stacked hexabenzocoronene units and are electroconductive upon oxidation. The use of amphiphilic hexabenzocoronenes with functional groups results in the formation of nanotubes with various interesting properties. Amphiphilic modifications of graphene-like molecules also allow the fabrication of mesoporous silica composites whose nanoscopic channels are completely filled with one-dimensional columnar assemblies of the $\pi$-electronic molecules. We believe our work will provide new strategies for the elaboration of new $\pi$-electronic soft nanomaterials that can be applicable to molecular-based electronic and optoelectronic devices. 
Acknowledgment. The author thanks Prof. Takuzo Aida (ERATO), Ms. Atsuko Kosaka (ERATO), Dr. Wusong Jin (ERATO), Dr. Jonathan P. Hill (ERTAO), Dr. Jin Motoyanagi (ERATO), Dr. Yohei Yamamoto (ERATO), Mr. Akihiro Okabe (ERATO), Dr. Noriyuki Ishii (AIST), Prof. Toshikazu Takigawa (Kyoto Univ.), and Dr. Kinji Asaka (AIST) for active collaboration.

\section{REFERENCES}

1. K. S. Novoselov, A. K. Geim, S. V. Morozov, D. Jiang, Y. Zhang, S. V. Doubonos, I. V. Grigorieva, and A. A. Firsov, Science, 306, 666 (2004).

2. K. S. Novoselov, A. K. Geim, S. V. Morozov, D. Jiang, M. I. Katsnelson, I. V. Grigorieva, S. V. Doubonos, and A. A. Firsov, Nature, 438, 197 (2005).

3. Y. Zhang, Y.-W. Tan, H. L. Stormer, and P. Kim, Nature, 438, 201 (2005).

4. "Carbon Nanotubes: Synthesis, Structure, Properties, and Applications," M. S. Dresselhaus, G. Dresselhaus, and P. Avouris, Ed., Springer-Verlag, Berlin, 2001.

5. S. Iijima, Nature, 354, 56 (1991).

6. S. Iijima and T. Ichihashi, Nature, 363, 603 (1993).

7. A. J. Berresheim, M. Müller, and K. Müllen, Chem. Rev., 99, 1747 (1999).

8. M. D. Watson, A. Fechtenkötter, and K. Müllen, Chem. Rev., 101, 1267 (2001).

9. C. D. Simpson, J. Wu, M. D. Watson, and K. Müllen, J. Mater. Chem., 14, 494 (2004).

10. A. C. Grimsdale and K. Müllen, Angew. Chem., Int. Ed., 44, 5592 (2005).

11. R. H. Baughman, A. A. Zakhidov, and W. A. de Heer, Science, 297, 787 (2002).

12. B. Vigolo, A. Pénicaud, C. Coulon, C. Sauder, R. Pailler, C. Journet, P. Bernier, and P. Poulin, Science, 290, 1331 (2000)

13. H. J. Barraza, F. Pompeo, E. A. O'Rear, and D. E. Resasco, Nano Lett., 2, 797 (2002).

14. D. Tasis, N. Tagmatarchis, V. Georgakilas, and M. Prato, Chem. Eur. J., 9, 4000 (2003).

15. H. Murakami and N. Nakashima, J. Nanosci. Nanotechnol., 6, 16 (2006).

16. J. C. Ma and D. A. Dougherty, Chem. Rev., 97, 1303 (1997).

17. T. Welton, Chem. Rev., 99, 2071 (1999).

18. P. Wasserscheid and W. Keim, Angew. Chem., Int. Ed., 39, 3772 (2000).

19. J. G. Huddleston, A. E. Visser, W. M. Reichert, H. D. Willauer, G. A. Broker, and R. D. Rogers, Green Chem., 3, 156 (2001).

20. T. Fukushima, A. Kosaka, Y. Ishimura, T. Yamamoto, T. Takigawa, N. Ishii, and T. Aida, Science, 300, 2072 (2003).

21. P. M. Ajayan, Chem. Rev., 99, 1787 (1999).

22. A. Krishnan, E. Dujardin, T. W. Ebbesen, P. N. Yianilos, and M. M. J. Treacy, Phys. Rev. B: Condens. Matter Mater. Phys., 58, 14013 (1998).

23. J.-P. Salvetat, G. A. D. Briggs, J.-M. Bonard, R. R. Bacsa, A. J. Kulik, T. Stöckli, N. A. Burnham, and L. Forró, Phys.
Rev. Lett., 82, 944 (1999).

24. M.-F. Yu, B. S. Files, S. Arepalli, and R. S. Ruoff, Phys. Rev. Lett., 84, 5552 (2000).

25. A. B. Kaiser, G. Düsberg, and S. Roth, Phys. Rev. B: Condens. Matter Mater. Phys., 57, 1418 (1998).

26. T. Fukushima, A. Kosaka, Y. Yamamoto, T. Aimiya, S. Notazawa, T. Takigawa, T. Inabe, and T. Aida, Small, 2, 554 (2006).

27. T. Katakabe, T. Kaneko, M. Watanabe, T. Fukushima, and T. Aida, J. Electrochem. Soc., 152, A1913 (2005).

28. Y. Zhao, Y. Gao, D. Zhan, H. Liu, Q. Zhao, Y. Kou, Y. Shao, M. Li, Q. Zhuang, and Z. Zhu, Talanta, 66, 51 (2005).

29. Y. Zhang, Y. Shen, J. Li, L. Niu, S. Dong, and A. Ivaska, Langmuir, 21, 4797 (2005).

30. T. Fukushima, K. Asaka, A. Kosaka, and T. Aida, Angew. Chem., Int. Ed., 44, 2410 (2005).

31. R. H. Baughman, C. Cui, A. A. Zakhidov, Z. Iqbal, J. N. Barisci, G. M. Spinks, G. G. Wallace, A. Mazzoldi, D. De Rossi, A. G. Rinzler, O. Jaschinski, S. Roth, and M. Kertesz, Science, 284, 1340 (1999).

32. J. M. Schnur, Science, 262, 1669 (1993).

33. D. T. Bong, T. D. Clark, J. R. Granja, and M. R. Ghadiri, Angew. Chem., Int. Ed., 40, 988 (2001).

34. T. Shimizu, M. Masuda, and H. Minamikawa, Chem. Rev., 105, 1401 (2005).

35. E. Clar, C. T. Ironside, and M. Zander, J. Chem. Soc., 1959, 142.

36. R. Oda, I. Huc, M. Schmutz, S. J. Candau, and F. C. MacKintosh, Nature, 399, 566 (1999).

37. J. P. Hill, W. Jin, A. Kosaka, T. Fukushima, H. Ichihara, T. Shimomura, K. Ito, T. Hashizume, N. Ishii, and T. Aida, Science, 304, 1481 (2004).

38. R. Rathore and C. L. Burns, J. Org. Chem., 68, 4071 (2003).

39. Y. Yamamoto, T. Fukushima, W. Jin, A. Kosaka, T. Hara, T. Nakamura, A. Saeki, S. Seki, S. Tagawa, and T. Aida, Adv. Mater., 18, 1297 (2006).

40. W. Jin, T. Fukushima, M. Niki, A. Kosaka, N. Ishii, and T. Aida, Proc. Natl. Acad. Sci. U.S.A., 102, 10801 (2005).

41. K. Akagi, G. Piao, S. Kaneko, I. Higuchi, H. Shirakawa, and M. Kyotani, Synth. Met., 102, 1406 (1999).

42. K. Tagami, M. Tsukada, Y. Wada, T. Iwasaki, and H. Nishide, J. Chem. Phys., 119, 7491 (2003).

43. M. M. Green, J.-W. Park, T. Sato, A. Teramoto, S. Lifson, R. L. B. Selinger, and J. V. Selinger, Angew. Chem., Int. Ed., 38, 3138 (1999).

44. T. Nakano and Y. Okamoto, Chem. Rev., 101, 4013 (2001).

45. "Materials-Chirality. Top. Stereochem," M. M. Green, E. W. Meijer, and R. J. M. Nolte, Ed., Wiley, 2003, vol. 24.

46. E. Yashima, K. Maeda, and T. Nishimura, Chem. Eur. J., 10, 42 (2004).

47. J. van Gestel, Macromolecules, 37, 3894 (2004).

48. Meijer and co-workers has independently reported a similar phenomenon at the same time; J. van Gestel, A. R. A, Palmans, B. Titulaer, J. A. J. M. Vekemans, and E. W. Meijer, J. Am. Chem. Soc., 127, 5490 (2005).

49. F. J. M. Hoeben, P. Jonkheijm, E. W. Meijer, and A. P. H. J. Schenning, Chem. Rev., 105, 1491 (2005).

50. T. Kato, N. Mizoshita, and K. Kishimoto, Angew. Chem., Int. Ed., 45, 38 (2006). 


\section{T. FUKUSHIMA}

51. C. G. Clark and K. L. Wooley, in "Dendrimer and Other Dendritic Polymers," J. M. J. Fréchet and D. A. Tomalia, Ed., Wiley, New York, 2002, p 147.

52. A. Mueller and D. F. O'Brien, Chem. Rev., 102, 727 (2002).

53. D. L. Gin, W. Gu, B. A. Pindzola, and W.-J. Zhou, Acc. Chem. Res., 34, 973 (2001).

54. W. Jin, T. Fukushima. A. Kosaka, M. Niki, N. Ishii, and T. Aida, J. Am. Chem. Soc., 127, 8284 (2005).

55. T. M. Trnka and R. H. Grubbs, Acc. Chem. Res., 34, 18 (2001).

56. Y. Kim, M. F. Mayer, and S. C. Zimmerman, Angew. Chem., Int. Ed., 42, 1121 (2003).

57. J. D. Hartgerink, E. Beniash, and S. I. Stupp, Science, 294, 1684 (2001).

58. Y.-Y. Won, H. T. Davis, and F. S. Bates, Science, 283, 960 (1999).

59. T. D. Clark, K. Kobayashi, and M. R. Ghadiri, Chem. Eur. J., 5, 782 (1999).

60. J. Motoyanagi, T. Fukushima, N. Ishii, and T. Aida, J. Am. Chem. Soc., 128, 4220 (2006).

61. N. Boden, R. J. Bushby, J. Clements, B. Movaghar, K. J. Donovan, and T. Kreouzis, Phys. Rev., 52, 13274 (1995).

62. M. O'Neill and S. M. Kelly, Adv. Mater., 15, 1135 (2003).

63. N. Boden and B. Movaghar, in "Handbook of Liquid Crystals," Vol. 2B, D. Demus, J. W. Goodby, G. W. Gray, H. W. Spiess, and V. Vill, Ed., VCH, Weinheim, 1998, p 781.

64. C.-Y. Liu, A. Fechtenkötter, M. D. Watson, K. Müllen, and
A. J. Bard, Chem. Mater., 15, 124 (2003).

65. T.-Q. Nguyen, R. Martel, P. Avouris, M. L. Bushey, L. Brus, and C. Nuckolls, J. Am. Chem. Soc., 126, 5234 (2004).

66. J. Motoyanagi, T. Fukushima, and T. Aida, Chem. Commun., 2005, 101.

67. C. Destrade, N. H. Tinh, H. Gasparoux, J. Malthete, and A. M. Levelut, Mol. Cryst. Liq. Cryst., 71, 111 (1981).

68. M. Yoshio, T. Mukai, H. Ohno, and T. Kato, J. Am. Chem. Soc., 126, 994 (2004).

69. T. Tajima and T. Aida, Chem. Commun., 2000, 2399.

70. A. Okabe, M, Niki, T. Fukushima, and T. Aida, Chem. Commun., 2004, 2572.

71. R. Ryoo, S.-H. Joo, and S. Jun, J. Phys. Chem. B, 103, 7743 (1999).

72. G. Zheng, H. Zhu, Q. Luo, Y. Zhou, and D. Zhao, Chem. Mater., 13, 2240 (2001).

73. A. Okabe, M. Niki, T. Fukushima, and T. Aida, Chem. Lett., 35, 228 (2006).

74. H. Bengs, M. Ebert, O. Karthaus, B. Kohne, K. Praefcke, H. Ringsdorf, J. H. Wendroff, and R. Wüstefeld, $A d v$. Mater., 2, 141 (1990).

75. N. Boden, R. J. Bushby, and J. Clements, J. Chem. Phys., 98, 5920 (1993).

76. A. Okabe, T. Fukushima, K. Ariga, and T. Aida, Angew. Chem., Int. Ed., 41, 3414 (2002).

77. "Handbook of Organic Conductive Molecules and Polymers, Vol. 1: Charge Transfer Salts, Fullerenes and Photoconducters," H. S. Nalwa, Ed. Wiley, New York, 1997.

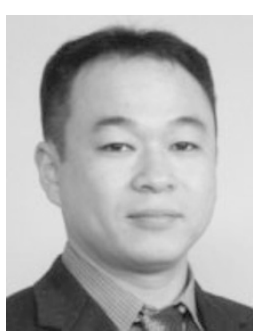

Dr. Takanori Fukushima was born in 1969. He received a B.S. degree in 1992 and a Ph.D in 1999 from Tohoku University under the direction of Professor Tsutomu Miyashi. In this period, he was a JSPS Research Fellow in 1995-1996 and began an academic career as a Research Associate at Tohoku University in 1996. In 2001, he moved to the JST ERATO project "Aida Nanospace" as a researcher. Since 2004, he has been a Group Leader of this project. He received SPSJ Wiley Award (2005) from the Society of Polymer Science, Japan. His research interests include the development of organic materials with electronic and optoelectronic functions. 